\title{
A ARQUEOLOGIA DA REPRESSÃO NO CONTEXTO DAS DITADURAS MILITARES DA ARGENTINA, URUGUAI B BASIL
}

\section{A U T O R}

Giullia Caldas dos Anjos

anjos.giullia@gmail.com
Graduanda do Curso de Bacharelado em História pela UFPel. Bolsista de Iniciação Científica FAPERGS.

\section{R E S U M O}

Este artigo propõe-se a analisar a chamada "arqueologia da repressão" no Uruguai, na Argentina e no Brasil, a partir de obra de alguns autores que elegeram esse tema enquanto objeto de estudo, como, por exemplo, a de Pedro Paulo Abreu Funari, Andrés Zarankin e José Alberioni dos Reis, "Arqueologia da repressão e da resistência: América Latina na era das ditaduras (décadas de 1960-1980)". Este artigo estrutura-se em quatro partes, abrangendo delimitação conceitual; breve histórico a respeito do período ditatorial nos três países tratados; como é trabalhada a arqueologia da repressão nos países em questão; e, por fim traçarei um paralelo entre a forma pela qual é visto este tipo de arqueologia em cada país, de que forma o seu estudo afeta as sociedades e qual é a importância que assumem tais evidências para estes países, que só muito recentemente, retomaram o estado de direito.

Palavras-chave: Arqueologia da Repressão; Ditadura; Resistência.

\section{A B S T R A C T}

This paper proposes to examine the so-called "archaeology of repression" in Uruguay, Argentina and Brazil, from the work of some authors who chose this subject as an object of study, such as Pedro Paulo Abreu Funari, Andrés Zarankin and José Alberioni dos Reis, "Archaeology of Repression and Resistance: Latin America in the era of dictatorships (decades of 1960 -1980)" . This article is divided into four parts, covering conceptual delimitation; brief history about the dictatorial period treated in the three countries, how the archaeology of repression is crafted in the countries concerned, and finally, I'll draw a parallel between the way it is seen this kind of archaeology in each country, how this study affects societies and which is the importance of such evidence for these countries, which have very recently taken over the rule of law.

Keywords: Archaeology of Repression; Dictatorship; Resistance.

\section{N T R O D U Ç Ã O}

Sabe-se que a história é escrita pelos vencedores e para os vencedores, e esses acreditam que sua história é "a história". Porém, os vencidos - ou as minorias - buscam, de certa forma, "reconstruir o destruído a partir dos

1 BENJAMIN (1991, apud FERREIRA, 2008, p. 42) escombros acumulados pela marcha triunfal dos vencedores" ${ }^{1}$. Essa História, dita tradicional, mostra-se invariavelmente parcial devido ao fato de ater-se às fontes geradas pelos que detêm o poder. Dessa forma, são relegados ao 
2 A história latino-americana é pródiga do ponto de vista da existência de regimes ditatoriais. Todavia, a abordagem que aqui iremos desenvolver centrase fundamentalmente no caso das ditaduras militares que se estenderam durante as décadas de 1960 a 1980 no Brasil, Argentina, Uruguai e Paraguai.

\footnotetext{
3 A esse respeito, recentemente foi publicado um artigo referente a Guerra do Araguaia (PEIXOTO, 2011)
}

anonimato todos aqueles grupos considerados desimportantes, como é o caso das minorias étnicas ou raciais e as classes oprimidas.

Coincidimos com Foucault (1997) quando este afirma que a história não deve ser estudada de maneira contínua, posto que esta deve ser considerada em sua descontinuidade. Destarte, o historiador não almeja a totalidade, pois ela não pode de fato ser alcançada. O que importa é o acontecimento em sua dispersão temporal e como ele responde a um conjunto de práticas discursivas de uma época, produzindo efeitos de verdades que advêm de relações de força do campo do saber-poder.

É nesse sentido que ganham relevo outros campos do conhecimento que partem desse compromisso de busca de abordagens e de outras perspectivas para além das narrativas oficiais. Uma questão é crucial para delimitar o campo da reflexão que nos propomos desenvolver nesse artigo, a qual pode ser formulada nos seguintes termos: de que forma a arqueologia, enquanto campo do conhecimento e espaço de atuação sócio-profissional pode auxiliar as minorias étnicas e grupos subalternos no sentido de fazer com que a sua história seja reescrita? Segundo Matthew Johnson: "sólo la arqueología aborda la profundidad temporal necesaria para generar generalizaciones interculturales acerca de los procesos culturales de largo alcance" (2000, p. 18). Além disso, o mesmo autor afirma que a Arqueologia é um instrumento da revolução cultural e que, assim, poderia ajudar a emancipar as pessoas das ideologias repressivas (JOHNSON, 2000, p. 18). Por fim, basta dizer que uma escavação nunca é neutra, tendo em vista que os artefatos não podem simplesmente fazer nenhum relato, mas devem ser interpretados, fato que coloca a Arqueologia em questão. A Arqueologia pode dar conta dessa materialidade do passado e criticá-la. Por fim, afirma Johnson, "aunque no hace falta añadir que nunca podremos ser completamente explícitos acerca de nuestros prejuicios y nuestros apriorismos, no por ello no debemos internarlo". E assim, através do uso da arqueologia da repressão, é possível interpretar, criticar e reconstruir a história desses grupos.

A arqueologia da repressão pode então ser definida como uma busca dessas histórias ditas como não-oficiais, particularmente as que resultam do sofrimento de pessoas que experimentaram a opressão e a tortura nas mãos de seus algozes em meio ao período marcado pelos regimes ditatoriais, durante as décadas de 1960 a 1980, nos países que hoje integram o chamado Mercado Comum do Cone Sul ${ }^{2}$. Dessa forma, é possível procurar tanto locais de tortura ou campos de concentração, como também encontrar os restos de pessoas desaparecidas, dentre outros diversos elementos. A busca dessas evidências remete o público interessado (organizações da sociedade civil, familiares dos desaparecidos, movimentos sociais, etc.) a desvendar as circunstâncias relativas ao ato da tortura e desaparecimento das pessoas ${ }^{3}$.

Em última análise, supõe a possibilidade de retomar as formas pelas quais foi engendrado todo um complexo sistema de repressão montado pelas ditaduras militares latino-americanas, as quais, como hoje sabemos, estiveram irmanadas em torno da conhecida "Operação Condor", de que falarei posteriormente. 


\section{BREVE HISTÓRICO SOBREAS DITADURAS NA AR G E T I NA, UR U G U I E BRASIL}

As origens das ditaduras latino-americanas no período referido anteriormente encontram-se ineludivelmente ligadas aos efeitos da chamada "guerra fria", no qual o mundo se apresentava dividido entre o bloco de países comunistas, integrados ao Pacto de Varsóvia, e as nações capitalistas, signatárias do Tratado Atlântico Norte. Após a derrota norte-americana em Cuba e o episódio dos mísseis soviéticos, recrudesceu o medo dos EUA de "esquerdização" do continente. Os graves problemas sociais demandavam a implantação urgente de reformas de base - sobretudo a agrária - em meio a um cenário de efervescência política que se viu reforçado com a vinda de Che Guevara para o continente (1966), em sua frustrada tentativa

${ }^{4}$ Segundo Chagas (2006, p.92), A estratégia foquista consistia no deslocamento de um pequeno grupo de guerrilheiros para uma região inóspita às tropas regulares, onde se iniciaria um processo de ambientação e treinamento. Em seguida, o pequeno destacamento realizaria ações militares junto aos camponeses com dois objetivos: mostrar o caráter justo de sua luta e recrutar guerrilheiros entre as populações locais. de implantar o foquismo ${ }^{4}$ e a guerrilha rural na Bolívia. É desse modo que deve ser compreendida a estratégia norte-americana de apoiar política e logisticamente a ascensão de regimes militares, estendendo sua área de influência sobre estes países, comandados agora por ditaduras.

Na Argentina, o período da ditadura (1966 - 1983) iniciou-se a partir do movimento "Revolução Argentina", liderado pelo General Videla, e se constituiu através do golpe de Estado que derrubou o presidente Arturo Illia, no dia 28 de junho de 1966. Cabe ressaltar que todo este contexto é, na verdade, fruto de um processo que se inicia, na verdade, anteriormente, em 1955, momento em que cai o governo do general Juan Domingos Perón. Desde então "vinha ocorrendo um amplo e crescente processo de institucionalização do poder militar como ator político" (PRIORI, 2006).

Em 1966, a Junta Revolucionária, com os comandantes das três forças armadas, Tenente General Pascual A. Pistarini (Exército), Almirante Benigno I. Varela (Operações navais) e o Brigadeiro Major Teodoro Álvarez (Força aérea), toma o poder sob a prerrogativa de que

las fuerzas armadas, en cumplimiento de su misión de salvaguardar los más altos intereses de la Nación, deben optar, de inmediato, las medidas conducentes a terminar con este estado de cosas y encauzar definitivamente al país hacia la obtención de sus grandes objetivos nacionales. (CISNEROS, ESCUDÉ, 2000)

Dessa forma, se resolve constituir a Junta Revolucionária, destituir dos cargos o presidente e vice-presidente da República, e aos governadores e vice-governadores. Além disso, define-se a dissolução do Congresso Nacional, assim como as legislaturas provinciais. Outra medida importante é a dissolução de todos os partidos políticos do país (CISNEROS, ESCUDÉ, 2000). É na "Acta de la Revolución Argentina", que fica definido que quem exercerá o cargo de presidente da República será o Tenente General Juan Carlos Onganía.

Segundo Priori (2006), teria havido uma pequena pausa nessa ascensão do militarismo argentino no momento em que Perón e Isabelita Perón sucedem o governo de Héctor Cámpora, entre 25 de maio de 1973 e 24 de março de 1976. Juan Perón, que assumiu o governo através de eleições livres que emergem após a renúncia de Cámpora, morre após um ano, sucedendoIhe a então vice-presidente Maria Estela Martínez de Perón (Isabelita). Seu governo, segundo Priori, teria sido marcado pela forte disputa entre as forças 
5 Segundo a Constituição: "Tomar medidas prontas de seguridad en los casos graves e imprevistos de ataque exterior o conmoción interior, dando cuenta, dentro de las veinticuatro horas a la Asamblea General, en reunión de ambas Cámaras 0 , en su caso, a la Comisión Permanente, de lo ejecutado y sus motivos, estándose a lo que éstas últimas resuelvan". (Constitución de la República del Uruguay, Capítulo III, Artículo 168, § 17)

\footnotetext{
6 Foi um acordo realizado no dia 12 de fevereiro de 1972, onde Bordaberry aceita todas as exigências dos militares e a partir do qual se dava "a inserção das Forças Armadas no sistema político - mediante a coparticipação militar na condução do Estado" (PADRÓS, 2005, p. 360). Como resultado, nasce o COSENA (Conselho de Segurança Nacional).
}

de esquerda e de direita.

Porém, o auge da ditadura na Argentina se dá num segundo momento, após a queda de Izabelita Perón, no golpe militar no dia 24 de março de 1976. É nesse momento que uma nova Junta Militar, desta vez composta pelo general Jorge Videla, almirante Emílio Massera e o brigadeiro Orlando Agosti, instalam a ditadura permanente, conhecida pelo nome "Processo de Reorganização Nacional", sendo "a mais violenta e transformadora da história argentina" (SAIN, 2000 apud PRIORI, 2006).

A partir de então, percebe-se o endurecimento do regime, no que diz respeito à prática da tortura e da repressão pelo Estado autoritário. E foi apenas com a derrota na Guerra das Malvinas, que a Junta Militar se enfraqueceu e que se deu o retorno à democracia, com a eleição na qual Raúl Alfonsín assumiu o governo em dezembro de 1983, pondo fim a este período sangrento da recente história argentina.

Já no Uruguai, o período da ditadura está compreendido entre o início dos anos 1970 e o começo dos anos 1980. Para entender o processo é necessário conhecer os antecedentes do golpe de Estado de 1973 no Uruguai. Dessa forma, vale lembrar a presidência de Jorge Pacheco Areco, de 1967, que se inicia após a morte do então presidente, general Óscar Diego Gestido, até março de 1972, quando finalmente Ihe sucede Juan María Bordaberry.

O governo de Pacheco fez uso das chamadas "medidas prontas de segurança"5 para poder reprimir toda e qualquer agitação popular, como também a guerrilha do Movimento de Liberação Nacional-Tupamaros. Foi durante seu governo que se censuraram meios de comunicação como a imprensa escrita, além da proibição da atuação de qualquer partido de esquerda como o Partido Socialista Uruguaio. Como a Constituição de 1967 não permitia a reeleição imediata, a União Nacional Reelecionista uruguaia organizou, em 1971, um plebiscito para tentar reeleger Pacheco.

Porém, com medo de que essa medida não obtivesse sucesso, decidem indicar um substituto (Bordaberry) de acordo com o regime vigente. Como o plano de reeleger Pacheco não deu certo, Bordaberry acabou sendo eleito presidente do Uruguai. Durante seu governo, para manter-se no poder, aliouse com os setores mais conservadores, tanto no âmbito militar quanto civil, sendo que dessa forma era visível que o posicionamento dos militares no governo continuava a aumentar.

Em fevereiro de 1972, houve um conflito entre os militares do Exército e da Força Aérea e o então presidente Juan María Bordaberry, pois este não havia concordado com a nomeação feita pelos militares no sentido de colocar Antonio Francese como Ministro de Defesa. Porém, acaba cedendo e aceita a nomeação através do Acordo de Boiso Lanza ${ }^{6}$. Dessa forma, abre-se aos militares um amplo leque de possibilidades de exercer o poder. Esse processo, na opinião de Padrós (2005, p. 360), consiste no fato de que "formalmente, governavam os civis, entretanto, de fato, os militares se haviam aquinhoado de boa parte do poder".

Foi então, a partir de 1973, que as forças militares passaram a exercer controle político pleno sobre a população. No dia 27 de junho de 1973, Bordaberry e as Forças Armadas fecham o Senado e a Câmara dos Deputados. Em junho de 1976, Bordaberry encaminha propostas de renovação da ordem constitucional, dentre as quais, destaca-se a eliminação dos partidos políticos,

a supressão da Constituição anterior e elaboração de uma nova carta 
magna. As Forças Armadas não aceitam esse encaminhamento, e tampouco concordam com a ideia de Bordaberry no que diz respeito à participação das Forças Armadas na política uruguaia futura. Mas se Bordaberry assumia que as Forças Armadas

deviam restringir-se à defesa da Segurança Nacional e do governo civil [...] as Forças Armadas entendiam que, para garantir a 'segurança para o desenvolvimento', deviam institucionalizar sua participação no governo como ator protagonista. (PADRÓS, 2005, p. 389, aspas no original)

Devido a essas divergências de opiniões e choque de interesses, as Forças Armadas explicitam seu poder ao destituir do cargo Bordaberry e substituindo-o, então, por Alberto Demicheli. Nesse sentido, as Forças Armadas publicam um documento no qual demonstram todas essas supostas divergências:

1. En que el Presidente no acepta el futuro funcionamiento de los Partidos Políticos tradicionales. Entiende que éstos no tienen cabida en el Uruguay del futuro. Propone en sustitución de la vigencia de ellos, la promoción y desarrollo de corrientes de opinión que en definitiva vendrían a ocupar el vacío dejado por aquéllos. En cambio las F.F.A.A. [Forças Armadas] no quieren compartir el compromiso, la responsabilidad histórica de suprimir los Partidos Políticos Tradicionales.

2. El señor Presidente de la República no acepta el pronunciamiento popular a través del voto, porque considera que esa práctica en las democracias actuales es algo superado, argumentado que el voto solamente se debe requerir a los ciudadanos a través de referendum o plebiscitos sobre puntos o temas específicos que el PE [Poder Executivo] considere conveniente. En contraposición a esto, las F.F.A.A. sostienen que la soberanía está radicada en la Nación y que, entre otras, una forma auténtica de expresión de esa soberanía, es el voto popular [...]

Surge así una incompatibilidad entre el pensamiento político de las F.F.A.A. y el del señor Juan María Bordaberry que impide a este continuar dentro de un proceso en el que no cree [...]. Por lo expuesto y para garantizar la continuidad del proceso cívico-militar en procura del Bienestar Nacional, se hace indispensable revitalizarlo con una actualización de los hombres responsables de esa conducción. En base a ello, las F.F.C.C. [Fuerzas Conjuntas] han retirado su confianza y apoyo al señor Juan María Bordaberry?

JUNTA DE COMANDANTES EM JEFE. Las Fuerzas Armadas al Pueblo Oriental. T II. El Proceso Político. (1978 apud PADRÓS, 2005, p.. 391)
É Alberto Demicheli, Presidente do Conselho do Estado, que firma o Ato Institucional $N^{\circ} 1$, suspendendo a convocação de eleições gerais e que cria o Consejo de la Nación, com o Ato Institucional $N^{\circ} 2$, que, conjuntamente com a Junta de Oficiais Generais e com o Conselho de Estado, indicavam o Presidente da República, os membros da Suprema Corte de Justiça, etc. Dessa forma, todos os cargos importantes e todos os organismos do Estado ficavam totalmente subordinados aos Oficiais Generais integrantes do Conselho da Nação (PADRÓS, 391).

A partir desse momento é que se inicia a fase mais dura da ditadura uruguaia, e conforme os Presidentes vão se opondo às intenções do Conselho da Nação, estes irão sendo sucessivamente substituídos. Este é o caso de Demicheli, que ao se opor ao Ato Institucional $N^{\circ} 4$, é substituído por Aparício 
8 DIREITO À MEMÓRIA E À VERDADE, P. 21.

${ }^{9}$ BRASIL, 2007, p. 22.
Mendez. Pelo Ato Institucional No 4, "se excluíam da vida política do país, por um prazo de 15 anos, cerca de 15 mil cidadãos" (PADRÓS, p.391).

Após outros diversos Atos Institucionais e muita repressão política, firma-se, em 1984, o acordo do Pacto do Clube Naval, entre Gregorio Álvarez, o Partido Colorado, Frente Ampla e a União Cívica. Este Pacto permitiu o retorno do regime democrático ao Uruguai. Marcou, ainda, o final do período ditatorial no país e também as bases para operar a tão sonhada transição à democracia.

No Brasil, o regime militar desenvolveu-se entre 1964 e 1985, desdobrando-se em três grandes fases. A primeira inicia-se com o golpe de Estado em 1964, que depôs o governo do gaúcho João Goulart, herdeiro político do trabalhismo de Getúlio Vargas. Nesse momento, os militares das Forças Armadas, vindos da Escola Superior de Guerra (ESG), encontravam-se em franca disputa, ainda que internamente, sobre como organizar-se-ia a administração do governo estatal. ${ }^{8}$ É a partir do Ato Institucional $N^{0} 1$ que se percebe o caráter repressivo do governo militar. Isso se percebe através das consequências desse Ato, entre as quais figuram em destaque a "cassação de mandatos, suspensão dos direitos políticos, demissão do serviço público, expurgo de militares, aposentadoria compulsória, intervenção em sindicatos e prisão de milhares de brasileiros". ${ }^{9}$ Nesse sentido, vale mencionar a Doutrina de Segurança Nacional, que foi uma

tentativa de fundamentar conceitualmente a suspensão das garantias constitucionais, a limitação das liberdades individuais, a introdução da censura aos meios de comunicação e a repressão total aos que se opunham por meio de atividades clandestinas. (BRASIL, 2007, p. 22).

O que se pode perceber com essa Doutrina de Segurança Nacional é a mudança do foco "inimigo" para o Estado, que agora passa de agente externo para interno, de forma a legitimar a repressão. Quanto à segunda fase da ditadura, ao final de 1968, é quando se dá a implantação do Ato Institucional $\mathrm{N}^{05}$, durante o governo de Costa e Silva, e que levou ao ápice do endurecimento do regime, agora então marcado por uma total repressão e prática da tortura. Fato que pode ser percebido também durante o governo de Medici, de 1969 a 1974, caracterizado pelos chamados "anos de chumbo".

Já a terceira fase da ditadura no Brasil começa com a posse do general Geisel, em 1974. Embora no início de seu governo, a repressão e tortura ainda fossem algo cotidiano, pode-se perceber, durante sua administração, uma "distensão lenta, gradual e segura". ${ }^{10}$ Nesse momento, é abolido o Ato Institucional $\mathrm{N}^{0} 5$ e a liberdade de imprensa pouco a pouco ia sendo devolvida. Oficialmente, foram reconhecidas aproximadamente 200 pessoas assassinadas pela ditadura. 


\title{
PROJETOS NUNCA MÁSCOMO PARTE CONSTITUIDORA DE MEMÓR I AS EM B LEMÁTICAS
}

Os Projetos Nunca Más, segundo Joffily (2010, p.1), operam "como um vetor de constituição de uma determinada memória emblemática sobre o legado dos governos militares". Como memórias emblemáticas, entenda-se,

${ }^{11}$ STERN (2000 apud JOFFILY, 2010). segundo o conceito de Stern ${ }^{11}$, como sendo

\begin{abstract}
aquelas que organizam e articulam várias memórias soltas a um determinado processo histórico, atribuindo a elas um sentido maior. Reúnem através de critérios de seleção e de uma determinada linha interpretativa, uma série de memórias individuais e coletivas, definindo os contornos do que deve ser incorporado e do que deve ser esquecido. (STERN (2000 apud JOFFILY, 2010, p. 1)
\end{abstract}

${ }^{12}$ BAUER (2008, p. 4).

Foi durante a transição política das ditaduras que se deu a criação das diversas comissões de desaparecidos em ambos países. Na Argentina, a Comissión Nacional sobre la Desaparición de Personas, foi criada pelo presidente Raúl Alfonsín, em 1983, através do decreto $187 .{ }^{12}$ Estas comissões, para Patricia Valdez,

\begin{abstract}
se crean en momentos históricos de recuperación del estado de derecho, con el advenimiento de un régimen democrático $\mathrm{o}$ al producirse intervenciones internacionales que tienen como misión apoyar procesos de paz y establecer premisas básicas para la convivencia. Su creación tiene el objetivo de investigar los hechos, conocer las causas que los motivaron y establecer responsabilidades de los diversos sectores involucrados. (VALDEZ, 2007 apud BAUER, 2008, p. 5)
\end{abstract}

Em 1984, na Argentina, foi disponibilizado pela primeira vez o Informe da CONADEP, que recebeu o nome de Nunca Más. Esse título "inspirou o grupo brasileiro envolvido com a sistematização dos processos da Justiça Militar a modificar o nome do projeto Testemunhos Pela Paz para Brasil:

13 JOFFILY (2010, p. 4). nunca mais". ${ }^{13}$

Esse título foi utilizado por diversos países. Dessa forma "iniciava-se uma espécie de filiação a um objetivo compartilhado entre nações latinoamericanas egressas de períodos ditatoriais: que as barbáries cometidas

${ }^{14}$ JOFFILY (2010, p. 4). pelas ditaduras militares não viessem a se repetir". ${ }^{14}$ No Uruguai, foi o Servicio de Paz y Justicia, fundado em 1981, o responsável pela realização do Informe Nunca Más, viabilizado em 1989, e que tinha o objetivo de "conocer

${ }^{15}$ SERPAJ (1989, p. 5-6). a fondo, en toda su magnitud la catástrofe padecida". ${ }^{15}$

No Brasil, desde 1979, a Arquidiocese de São Paulo e diversos ativistas dos direitos humanos vinham realizando muitas pesquisas e levantamento de documentos e depoimentos que culminaram na publicação do Informe ${ }^{16}$ MARCHESI (2001). Brasil: Nunca Mais, em 1985. ${ }^{16}$ Atualmente a Comissão Especial sobre Mortos e Desaparecidos vem realizando publicações de diversos materiais a respeito da ditadura, como o livro "Direito à Memória e à Verdade", "Luta, substantivo feminino", entre outros.

De acordo com os dados do CONADEP de 2007, de um total de 8691 desaparecidos na Argentina, a prevalência de homens (70\%) é bastante expressiva. A mesma fonte indica que que $59 \%$ desse universo é formado 
por jovens entre 21 e 30 anos de idade.

A Fig.1 indica que o recrudescimento da ditadura militar argentina ocorre fundamentalmente entre os anos 1976 a 1978, período que concentra mais de $85 \%$ dos desaparecidos.

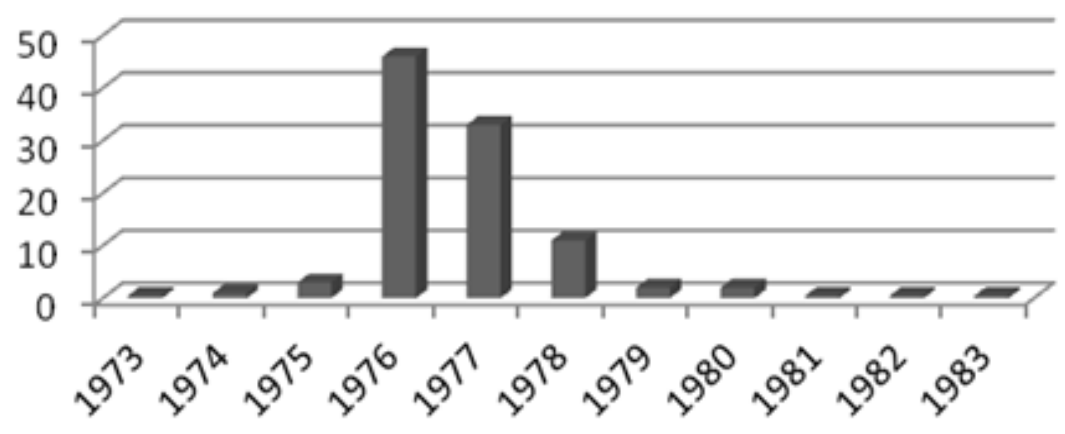

Figura 1: Porcentagem dos desaparecidos por ano, Argentina.

Fonte: CONADEP, 2007.

Na Fig.2, apresentamos os dados referentes à ocupação dos desaparecidos da Argentina. Podemos que perceber que a maior parte é composta de operários (30,2\%), seguido de estudantes (21\%), ou seja, mais da metade dos desaparecidos na Argentina são ou operários ou estudantes.

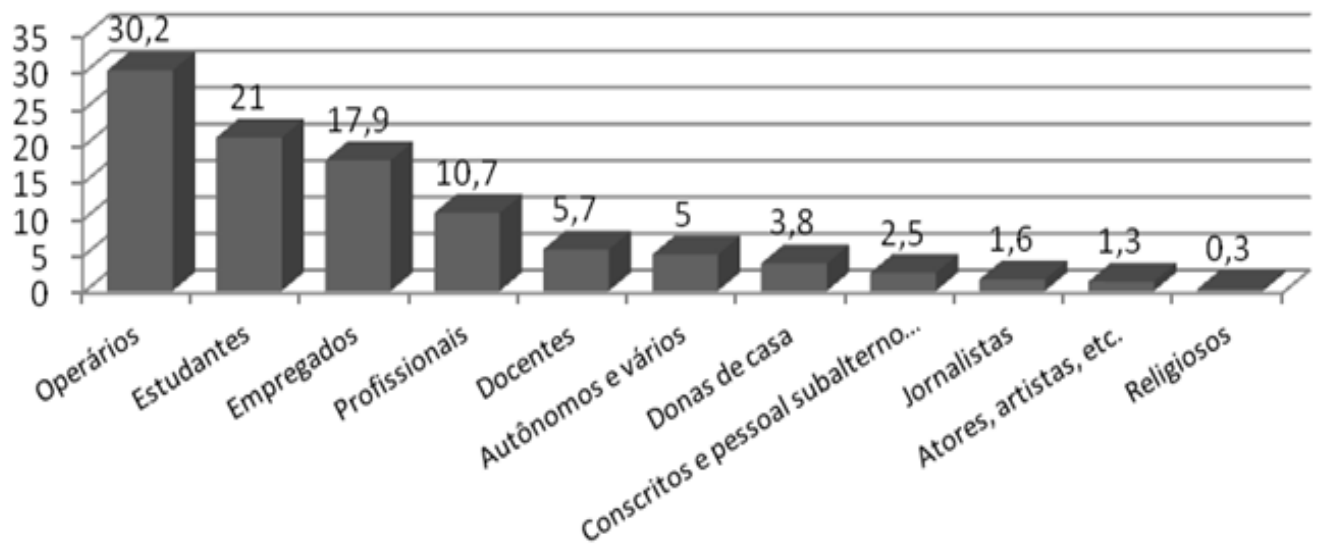

Figura 2: Porcentagem da ocupação dos desaparecidos, Argentina. Fonte: CONADEP, 2007.

Muito semelhante é o caso do Uruguai (Fig. 3) no que diz respeito ao desaparecimento de pessoas tendo em vista o ano. Nesse caso, não são 85\% - 1976-1978 - mas sim, 95\% dos desaparecidos no Uruguai se deram no mesmo período.

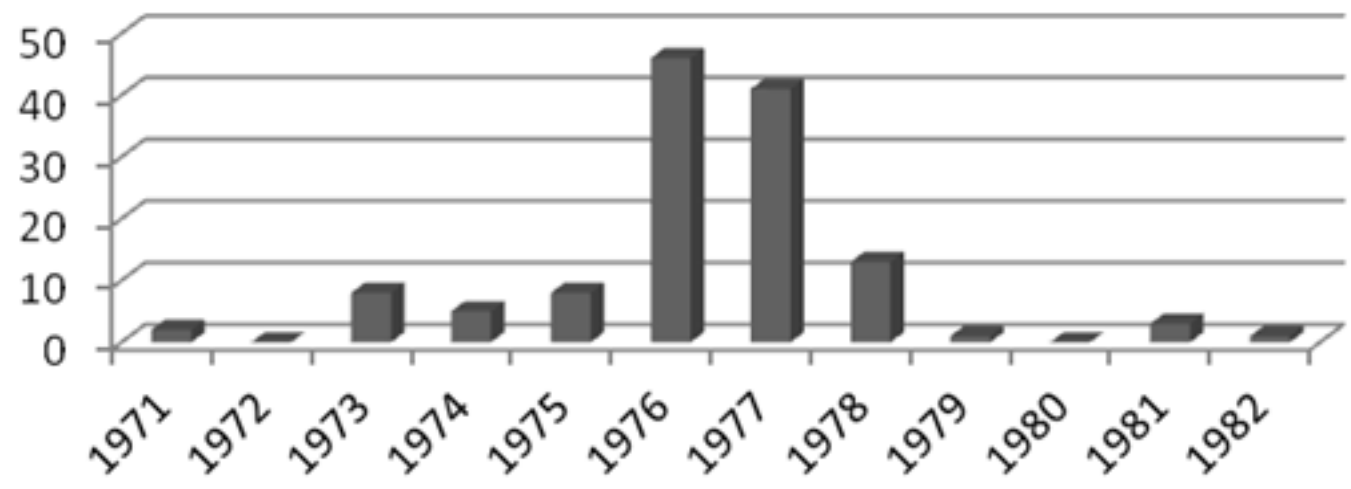

Figura 3: Porcentagem de desaparecidos por ano, Uruguai.

Fonte: SERPAJ, 2006. 
Enquanto os dados da Argentina e do Uruguai destacam os desaparecidos, no Brasil o que se percebe é a análise dos torturados. Quanto à distribuição por gênero, percebe-se que enquanto que na Argentina cerca de 70\% dos desaparecidos são homens e no Uruguai, segundo o SERPAJ de 1989, são 76\%, no Brasil, segundo o Projeto Brasil: Nunca Mais, de um total de 1.843 torturados, $79 \%$ são do sexo masculino.

A seguir, apresento alguns dados retirados do Projeto Brasil: Nunca Mais, no que diz respeito à tortura no Brasil. Na Fig.3, estão expostas as denúncias de tortura por ano, e é possível destacar que, no período de 1969 a 1973 , foram realizadas as denúncias de quase $75 \%$ do total (período de 1964 a 1977).

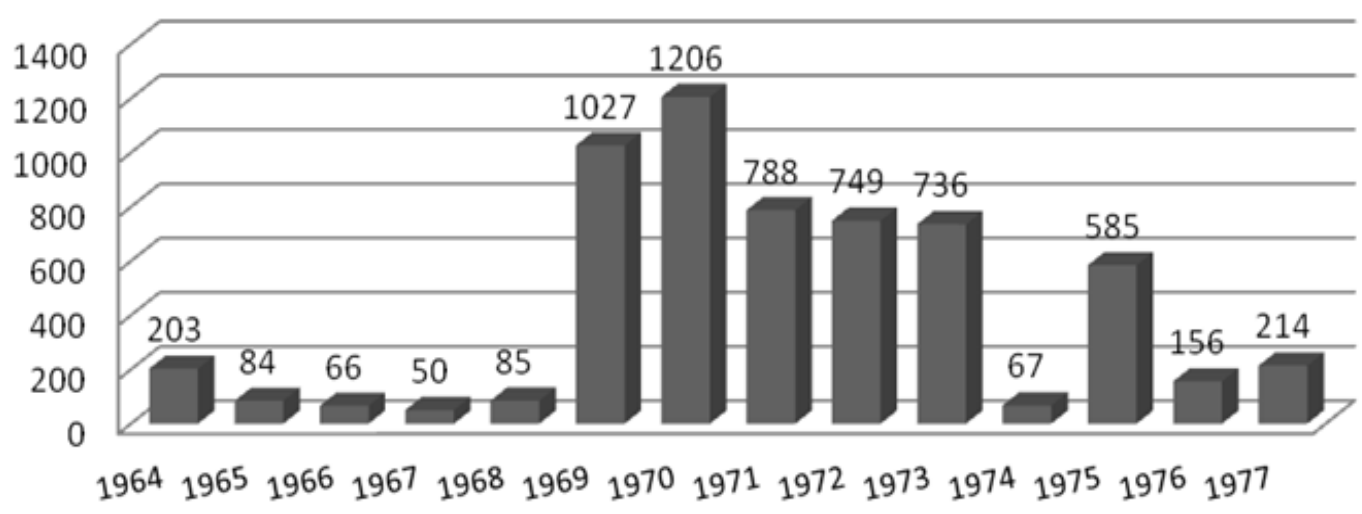

Figura 3: Denúncias de Tortura por ano.

Fonte: Brasil: Nunca mais, 1985.

Classificando os torturados no Brasil por faixa etária, é possível confrontar os dados com os desaparecidos da Argentina e perceber o envolvimento de jovens nesse contexto. Enquanto na Argentina, cerca de $58 \%$ dos desaparecidos eram jovens (21-30 anos), no Brasil, segundo o Projeto Brasil: Nunca Mais de 1985, essa mesma faixa etária compreendia mais de $45 \%$ dos torturados.

A Fig.4 demonstra o número absoluto de torturados por tipo de tortura. O relatório do Projeto Brasil: Nunca Mais, totaliza 310 tipos diferentes de torturas. Porém, aglutina-os em diversos grupos, que são representados abaixo. Dentre as coações morais e psicológicas temos, como exemplo, ameaças diversas, ambientalização de terror, pressão moral , vexames, cuspir no rosto, humilhar, insultar, difamar, etc.

Dentre as coações físicas temos agressão, açoite, uso de cassetete, chibata, chicote, coronhadas, torturas frente à esposa, torturar os filhos, esposa, pais, etc. Quanto às violências sexuais, existem das mais variadas no relatório, como por exemplo, furar órgãos genitais com agulhas, uso de presilhas nos órgãos genitais, estuprar esposa presa, etc.

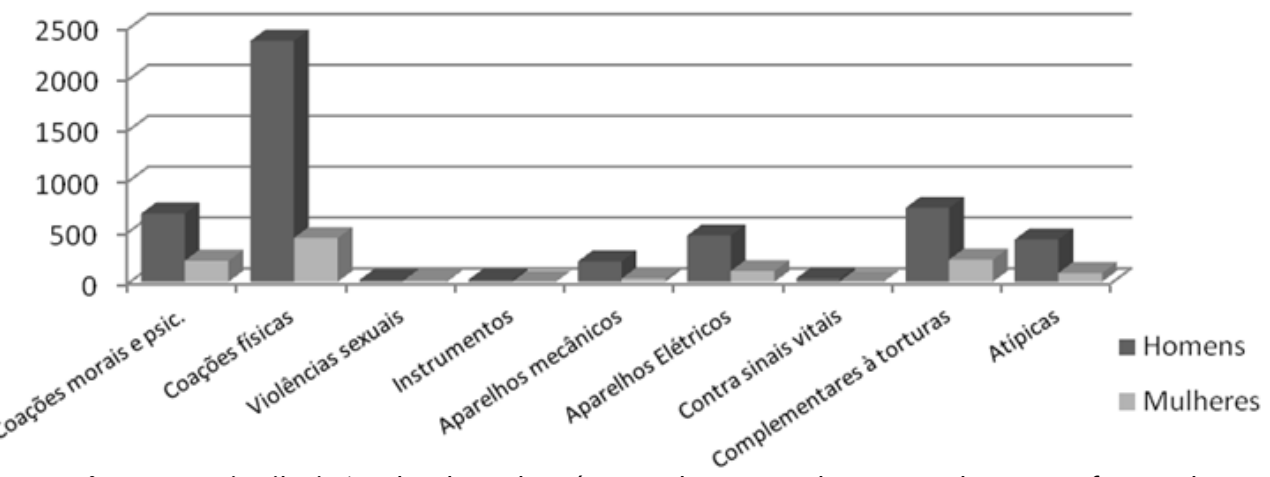

Figura 4: Distribuição absoluta do número de torturados segundo sexo e forma de torturas. 
Quando, na Fig.4, destaco instrumentos, refiro-me às torturas com instrumentos perfuro-contundentes, cortantes e queimantes, como dedos e juntas marteladas, enfiar canivete nas unhas, queimaduras com cigarros, maçarico e papel aceso, dentre outras. No que diz respeito às torturas com aparelhos mecânicos, constam, sobretudo, o uso de crucifixo, corda amarrada no pescoço e genitais, pau de arara, pendurar pelos punhos, pendurar pelos pés com os braços suspensos, etc.

Ao falar sobre as torturas com aparelhos elétricos, refiro-me à cadeira do dragão e aos diversos choques elétricos. Além disso, contra os sinais vitais são destacados diversos afogamentos, asfixia, uso de esponja de água na boca, enforcamento, dentre outros. Com relação às torturas complementares às torturas, são destacadas: o uso de água para piorar choques, ácido no rosto, álcool mais ventilador, uso de amoníaco na boca, gás asfixiante, injeção de éter, etc. No que diz respeito às torturas atípicas, constam as que incluem o uso de diversos animais, como baratas, cães, cobras, ratos, etc., além de obrigar a pessoa torturada a cavar a própria sepultura, obrigar a comer os próprios excrementos, beber urina, dentre outros.

Os dados da Figura 4 indicam ainda que os mais atingidos foram os homens, com um total de 4.918, sendo que deste número 2.369 sofreram coações físicas. Já com relação às mulheres, temos um total de 1.098 pessoas, sendo que destas 431 também sofreram coações físicas. Pode-se perceber, então, o sadismo existente nesse contexto e sua materialização durante o período. Seria absolutamente impossível resumir no curto espaço que aqui dispomos a diversidade de formas de tortura utilizadas no Brasil e nos demais países analisados pelos órgãos de repressão. A tarefa que nos impõe agora é no sentido de abordar o tema da arqueologia da repressão no âmbito dos três países aqui analisados.

\section{ARQUEOLOGIA DA REPRESSÃO NA ARGENTINA URUG UA I E B RASI L}

A Arqueologia da repressão é apontada como estudo da materialidade do período relativo às ditaduras militares, permitindo uma nova interpretação para o quadro social e político dominante entre as décadas de sessenta e setenta. Sabe-se que na Argentina funcionaram, no período da ditadura, cerca de 340 CCDs (Centros Clandestinos de Detenção). Trata-se de aparelhos instalados geralmente em prédios já existentes, sendo lugares destinados à repressão e ao terror praticado pelo Estado (agentes civis ou militares). Mas tais locais cumpriam outros propósitos que não os de deter, corrigir e entregar o indivíduo de volta à sociedade, mas, sim, destruir e eliminar por completo todos os que eram considerados como "inimigos do Estado" por praticarem atos supostamente terroristas. Zarankin e Niro (2008) apontam importantes diferenças existentes entre os campos de concentração em geral e os CCDs:

[...] a diferença é que, enquanto um campo de concentração é "um lugar" que se rege por convenções (ao menos deve fazê-lo segundo uma série de convenções internacionais que garantem algum respeito aos prisioneiros), o CCD não possui nenhuma - ao menos oficialmente - porque simplesmente não existe institucionalmente. Sua condição de clandestino lhe outorga a vantagem da invisibilidade e da impunidade, 
${ }^{17}$ ZARANKIN \& NIRO, 2008, p. 206.

\footnotetext{
18 "O "inimigo interno" podia estar localizado em outro país (exilado, escondido), assim como o "inimigo interno" de outra nação também precisava ser combatido não somente pelo país que o abriga. Este era o fundamento da criação da Operação Condor". (FERNANDES, 2009, p. 2)

${ }^{19}$ MAZZ, 2008 p. 171.

20 MAZZ, 2008 p. 172 (destaque no original).

${ }^{21}$ MAZZ, 2008, p. 173.
}

convertendo-o em um "não-lugar" para aqueles que se encontram dentro de seu espaço. (ZARANKIN e NIRO, 2008, p. 194; aspas no original)

Em 2003 foi aprovado o projeto de escavação de um dos CCDs existentes em Buenos Aires - o Club Atlético. Tratava-se de desvendar a lógica da arquitetura deste dispositivo. Segundo Zarankin e Niro, no primeiro nível estavam instalados dois escritórios correspondendo à esfera burocrática do CCD. No segundo nível, ou seja, abaixo do primeiro (subsolo) estavam as salas de detenção coletiva. No nível abaixo estavam outras celas e, logo depois, as salas de tortura. Dessa forma, nota-se a questão emblemática da constituição da estrutura do Club Atlético. As salas de tortura, ao serem colocadas no espaço intermediário entre as celas, como mostram os autores, acarretam grande transtorno aos detidos. Permitem evidenciar, de forma ineludível, a "materialização do sadismo implícito no projeto arquitetônico do CCD". ${ }^{17}$

No Uruguai, no entanto, como demonstra Mazz (2008), a conformação dos locais onde ficavam retidos os presos políticos deu-se através de duas formas. Num primeiro momento, esses pontos de retenção e repressão política estavam centrados em lugares militares. Não obstante, num segundo momento, já sob a égide da "Operação Condor"18, essa localização é modificada e conforma-se, então, uma rede de lugares clandestinos para onde são levados os presos políticos. Dessa forma, os restos de desaparecidos formam um "documento fundamental"19 que auxilia na interpretação da história extra-oficial do período ditatorial.

Como destaca o autor, "a localização do enterramento clandestino de um detido desaparecido pode transformar um espaço, até agora irrelevante e passível de ser considerado um 'não-lugar' [...], em um 'lugar de repressão'"20. Foram realizados no Uruguai diversos estudos forenses em valas comuns, obtendo destaque os cemitérios de Colônia do Sacramento e da cidade de Castillos. Entretanto, até agora não foi possível recuperar vestígios significativos, especialmente devido ao "pacto do silêncio" ${ }^{21}$. Nesse contexto, a arqueologia forense e a arqueologia da repressão destacam-se como alicerces para ressemantização do significado atribuído aos restos encontrados e como auxiliares tanto da história, por dar voz aos silenciados, como da justiça aos familiares e amigos dos desaparecidos.

No Brasil, pouco se avançou em termos de uma arqueologia do período ditatorial. É imperativo reconhecer a importância desses estudos para a sociedade, buscando respostas a questionamentos que ainda atormentam a população de forma geral. Porém, como apontam Funari e Oliveira (2008, p. 148), "não se pode estudar bem a repressão sem um exame das condições que levaram a arqueologia em nosso país a abster-se do tema por tanto tempo e de maneira tão persistente". É necessário, portanto, dar importância para essa área que ao passar do tempo ganha cada vez mais destaque. No Brasil, a pesquisa arqueológica no estudo do período da ditadura ainda está em sua infância, como resultado das diversas armadilhas jurídicas e políticas colocadas pelo Estado autoritário.

É mister afirmar que a arqueologia da repressão corresponde a um campo do conhecimento pouco valorizado. Isso se deve, em parte, a que muitos personagens que atuaram nas ditaduras latino-americanas ainda estão no poder. Recentemente alguns pesquisadores estão se dedicando ao tema, considerando que esse esforço há que superar as fronteiras 
internacionais diante do fato de que muitas pessoas desapareceram em outros países, sob o império do terror implantado pela "Operação Condor".

Mas essa luta demanda recursos e decisão política, algo que não se pode circunscrever a uma mera ação indenizatória de alguns poucos casos em que o Estado se viu obrigado a reconhecer tais práticas, diante da força das evidências levantadas por arqueólogos, antropólogos forenses e outros atores que se envolveram nesta verdadeira cruzada em busca da verdade. Entre 1964 e 1979, o projeto Brasil Nunca Mais contabilizou 7.367 acusados judicialmente, 10.034 atingidos na fase de inquérito, 130 pessoas banidas, 4.862 cassados e pelo menos 245 estudantes expulsos da universidade, sendo que apenas 357 mortos foram efetivamente reconhecidos (BRASIL, 2007, p.30).

\section{CONSIDERAÇÕ ES FINA IS}

Algumas de 1960 e 1970. Todavia, não cabe dúvida de que a arqueologia da repressão representa uma via para fazer emergir estes fatos e buscar elucidar uma outra narrativa contrapondo-se à oficial a respeito de nosso passado, sobretudo quando é evidente a queima de documentos e de arquivos no interior dos quartéis e dependências militares.

Os dados e informações aqui apresentados ilustram, de certa forma embora ainda seja necessário que se aprofundem as pesquisas no tema - a dimensão das atrocidades cometidas durante o regime militar. Todavia, não cabe dúvida de que nos encontramos diante de um imperativo indispensável para construir uma sociedade mais justa e equilibrada do ponto de vista político. Conhecer como funcionavam os aparelhos de repressão e os equipamentos de tortura é uma tarefa dolorosa, mas imprescindível para desvelar um país que a própria população desconhece.

\section{A GRADECIMEN TOS}

Agradeço o apoio institucional da FAPERGS (Fundação de Amparo à Pesquisa do Estado do Rio Grande do Sul) pela concessão de Bolsa de Iniciação Científica. Ao Prof. Dr. Lúcio Ferreira Menezes por todo o apoio e incentivo ao longo desses anos, pela leitura atenta e sugestões. 


\section{B I B L I O G R A F I A}

ARQUIDIOCESE DE SÃO PAULO. Projeto "Brasil Nunca Mais". Projeto A, 6 tomos, 12 volumes, São Paulo, Arquidiocese de São Paulo, 1985.

BAUER, C. S. A produção dos relatórios Nunca Mais na Argentina e no Brasil: aspectos das transições políticas e da constituição da memória sobre a repressão. Revista de História Comparada, v. 2, n. 1, 2008. Disponível em <http://www.hcomparada.ifcs.ufrj.br/revistahc/artigos/volume002_Num001_artigo004. pdf $>$. Acesso em: 17 de maio de 2011.

BRASIL, Comissão Especial sobre Mortos e Desaparecidos Políticos. Direito à Memória e à Verdade: Comissão Especial sobre Mortos e Desaparecidos Políticos, Brasília: Secretaria Especial dos Direitos Humanos, 2007. Disponível em: <http://www.presidencia.gov.br/estrutura_presidencia/sedh/>. Acesso em 12 agosto de 2009.

CHAGAS, F. Ação e revolução: os zigue-zagues estratégicos da VPR em 1968, In: Cadernos de Pesquisa do CDHIS, n³ 35, 2006, p. 91-100.

CISNEROS, A.; ESCUDÉ, C. Historia de las Relaciones Exteriores Argentinas. Tomo XIV. 2000. Disponível em: <http://www.ucema.edu.ar/ceieg/arg-rree/historia_indice14.htm>. Acesso em 06 de junho de 2011. COMISIÓN NACIONAL SOBRE LA DESAPARICIÓN DE PERSONAS (CONADEP). Nunca más: informe de la Comisión Nacional sobre la desaparición de personas. 8a edição, Buenos Aires: Eudeba, 2007.

FERNANDES, A. A perseguição além da fronteira: os órgãos de repressão e espionagem da ditadura brasileira para o controle dos exilados brasileiros no Uruguai. In: Estudios Historicos, Rivera: CDHRP, n. 1, maio de 2009. Disponível em: <http://dialnet.unirioja.es/servlet/articulo?codigo=3010812>. Acesso em 21 de maio de 2011.

FERREIRA, L. Patrimônio, pós-colonialismo e repatriação arqueológica. In: Ponta de Lança, São Cristóvão v.1, n. 2, abr-out, 2008. p. 37-62.

FOUCAULT, M. A Arqueologia do saber. $5^{a}$ Ed. Rio de Janeiro: Forense Universitária, 1997.

FUNARI, P. P. A.; OLIVEIRA, N. V. A arqueologia do conflito no Brasil. In: FUNARI, P. P.; ZARANKIN, A.; REIS, J. A. Arqueologia da repressão e da resistência: América Latina na era das ditaduras (décadas de 19601980), São Paulo: Annablume; Fapesp, 2008. p. 141-149.

FUNARI, P. P., OLIVEIRA, N., TAMANINI, E., Arqueologia pública no Brasil e as novas fronteiras, In: Praxis Archaeologica 3, 2008, p. 131-138.

FUNARI, P. P.; ZARANKIN, A.; REIS, J. A. Arqueologia da repressão e da resistência: América Latina na era das ditaduras (décadas de 1960-1980). São Paulo: Annablume; Fapesp, 2008, 215 p.

JOFFILY, M. Gender and political repression in Nunca Mas reports (Brazil, Argentina and Uruguay). In: XXIX Congresso Internacional da Latin American Studies Association (LASA), 2010, Toronto. Disponível em: $\quad$ <http://www.google.com.br/\#hl=pt-BR\&source $=\mathrm{hp} \& q=$ gender + and + political + repression $+\mathrm{in}+\mathrm{N}$ unca + mais + reports $+($ Brazil\%2C + Argentina\%2C + Uruguay + and $+C h i l e)+\% 2 B+J o f f i l y \& a q=f \& a q i=\& a-$ $q \mathrm{l}=\& o q=\& b a v=0 n .2, o r . r_{2} g c . r \_p w . \& f p=4 d f 07300 f e f c a e 45 \& b i w=1259 \& b i h=597>$. Acesso em 06 de junho de 2011.

JOHNSON, M. El sentido común no basta. In: JOHNSON, M. Teoría Arqueológica. Una introducción. Barcelona: Editorial Ariel, 2000. p. 15-27.

MARCHESI, A. A. "Las lecciones del pasado", memoria y ciudadanía en los informes "nuncamas". Informe final del concurso: Culturas e identidades en América Latina y el Caribe. Programa Regional de Becas CLACSO. 2001. Disponível em: <http://bibliotecavirtual.clacso.org.ar/ar/libros/becas/2000/marchesi. pdf>. Acesso em: 21 de maio de 2011.

MAZZ, J. M. L. Um olhar arqueológico sobre a repressão política no Uruguai (1971-85). In: FUNARI, P. P.; ZARANKIN, A.; REIS, J. A. Arqueologia da repressão e da resistência: América Latina na era das ditaduras (décadas de 1960-1980). São Paulo: Annablume; Fapesp, 2008, p.169-181.

PADRÓS, E. A. Como el Uruguay no hay... Terror de Estado e Segurança Nacional. Uruguai (1968-1985): do Pachecato à ditadura civil-militar. 2005. Tese (Doutorado em História) Universidade Federal do Rio Grande do Sul, Porto Alegre. (2 v.) 
PRIORI. A. Golpe Militar na Argentina: apontamentos históricos. In: Revista Espaço Acadêmico, n 59 , Abril. Disponível em: <http://www.espacoacademico.com.br/059/59priori.htm>. Acesso em 21 de maio de 2011.

SERVICIO PAZ Y JUSTICIA. Uruguay: nunca más. Informe sobre la violación de los Derechos Humanos (1972-1985). Montevideo: SERPAJ, 1989.

URUGUAI. Constitución de la República. Disponível em: <http://www.parlamento.gub.uy/constituciones/ const004.htm>. Acesso em: 28 de maio de 2011.

URUGUAI. PRESIDENCIA DE LA REPÚBLICA ORIENTAL DEL URUGUAY. Investigación Histórica sobre los detenidos desaparecidos. Montevidéu, 2006. Disponível em: <http://www.presidencia.gub.uy/_Web/ noticias/2007/06/2007060509.htm> Acesso em 17 de maio de 2011.

ZARANKIN, A.; NIRO, C. A materialização do sadismo: arqueologia da arquitetura dos Centros Clandestinos de Detenção da ditadura militar argentina (1976-83). In: FUNARI, P. P.; ZARANKIN, A.; REIS, J. A. Arqueologia da repressão e da resistência: América Latina na era das ditaduras (décadas de 1960-1980). São Paulo: Annablume; Fapesp, 2008, p. 183-210.

PEIXOTO, Rodrigo Corrêa Diniz. Memória social da Guerrilha do Araguaia e da guerra que veio depois. Boletim do Museu Paraense Emílio Goeldi. Ciências Humanas, v. 6, n. 3, p. 479-499, set.-dez. 2011. 